\title{
Disconnection of Ventriculoperitoneal Shunt after Mild Injury over the Catheter's Pathway: Two Cases
}

\author{
Claudia Marcela Restrepo Lugo ${ }^{1}$ Miguel Ángel Maldonado Morán ${ }^{1}$ Andreina Martinez Amado \\ Luis Rojas ${ }^{1}$ Erik Muñoz ${ }^{1}$ Juan Carlos Luque ${ }^{1}$ \\ ${ }^{1}$ Department of Neurosurgery, Central Military Hospital, Bogotá, \\ Address for correspondence Miguel Ángel Maldonado Morán, \\ Colombia \\ Department of Neurosurgery, Central Military Hospital, Transversal \\ 3a No. 49-00, Colombia Bogota D.C. 3486868, Colombia \\ (e-mail: miguel.mamoran@gmail.com).
}

Indian J Neurosurg 2018;7:46-50

\begin{abstract}
Keywords

- hydrocephalus

- catheter

- ventriculoperitoneal

- shunt

- injury

Hydrocephalus is present in 1 of every 1,000 newborns treated with ventriculoperitoneal shunts (VPSs) in the majority of cases. This procedure carries a high risk of complications. One of them is the mechanical disconnection of the system that leads to dysfunction of the shunt and implies neurologic changes that the neurosurgeon has to address as soon as possible. We present two cases of congenital hydrocephalus previously treated with ventriculoperitoneal shunts. The first patient was hit on the right side of his neck. The day after the event, the patient was hypoactive and unable to communicate properly with the examiner and his parents. The radiological cervical X-ray showed disconnection of the catheter at the cervical level. The second case was of a 37-year-old man with hydrocephalus managed with VPS for the first time at the age of 14 years, who was brought to emergency due to rapid onset of symptoms apparently associated with trauma related to a blow with a soccer ball; the patient's $X$-ray showed fracture of the catheter's path at the thoracic level. For both cases, surgical repair was needed. Results were good, and the patients showed rapid neurologic improvement.
\end{abstract}

\section{Introduction}

Hydrocephalus is a frequent multifactorial and complex medical condition that dilates the ventricles. The involvement of the ventricles could be caused by a congenital defect or acquired conditions that modify the production or reabsorption of cerebrospinal fluid (CSF) and cause an increase of intracranial pressure. The rate of hydrocephalus has been estimated to be 1 in 1,000 newborns, and it can be classified according to etiology as congenital hydrocephalus, acquired hydrocephalus, communicating hydrocephalus, and noncommunicating hydrocephalus.

Congenital hydrocephalus is the most common, approximately $70 \%$ among diagnosed patients. ${ }^{1}$ The treatment of choice is the implantation of a ventriculoperitoneal shunt
(VPS) to drain the excess fluids in the brain ventricles and reduce the intracranial pressure..$^{1,2}$ In the 1950 s before shunt management, $49 \%$ of patients died over a period of 20 years. ${ }^{3}$ This is important to keep in mind because the procedure has been shown to decrease the morbidity and mortality of this disease. However, the implantation of the VPS comes with a high risk of complications such as infection, catheter displacement, and system malfunction, which are the most common and the patient often requires surgery.

The most frequent cause of system malfunction is mechanical catheter obstruction by choroid plexus or glial tissue that grows inside the catheter, followed by mechanical disconnection. ${ }^{4}$ However, there are not enough reports as yet estimating the incidence of mechanical disconnection followed by mild trauma. received

October 26, 2016 accepted after revision

December 23, 2016

published online

April 12, 2017
DOI http://dx.doi.org/

10.1055/s-0037-1601355. ISSN 2277-954X.
Copyright @2018 Neurological

Surgeons' Society of India
License terms

$($ () (1) $\ominus \circledast$ 
This article reports on the mechanical disconnection of the VPS system in a pediatric patient associated with only a minor trauma to the catheter's pathway. The second case report involves an adult patient with apparent trauma at the thoracic level and subsequent disconnection of the system. We also describe the appropriate correction of the malfunction for both patients.

\section{Presentation of Cases}

\section{Case 1}

A 6-year-old child with a history of congenital hydrocephalus was managed by VPS for the first time at the age of 2 years and a year later for his 3-year-old revision. He was brought by his parents to the emergency services of the Central Military Hospital (Bogota, Colombia) due to hypoactivity and slowed speech after been hit by his sister on the right side of his neck the preceding day. During the physical examination, the patient was noted to have discontinuation of the valvular pathway at the level of the neck ( - Fig. 1). He was hypoactive, obeyed commands, and he did not communicate with the examiner. The rest of the neurologic examination was normal for his age.

During his stay in the emergency department, a set of radiologic images was taken. The chest X-ray showed disconnection of the system at the level of the neck, the place where the child was hit (-Fig. 2). The cranial and abdominal X-rays did not show abnormalities of the catheter ( - Figs. 3 and 4). Cranial computed tomography (CT) did not show acute hydrocephalus.

After these studies and the clinical manifestation of intracranial hypertension, the revision of the catheter at the cervical segment under general anesthesia was performed. The patient was positioned, and the surface of the right cervical area, cranium, right lateral chest, and abdomen were prepared aseptically for surgery. During surgery, it became evident that the valve catheter was disconnected at the cervical segment. The procedure showed that the catheter was functioning; therefore, there was only a need for secure the catheter at the cervical segment with monofilament nonabsorbable suture material.

The patient awoke active. Two hours after the procedure, he had improved dramatically, showing symptoms of normal activity, and he started speaking to his parents. He was discharged from the hospital 48 hours after the surgical repair. The patient continued follow-up visits every 2 months, showing adequate clinical evolution, a complete absence of symptoms associated with an increase in intracranial pressure, and appropriate functioning of the VPS system.

\section{Case 2}

The second patient was a 37-year-old man with a history of hydrocephalus managed by VPS for the first time at the age of 14 years. He was brought to the emergency department of the Central Military Hospital due to the rapid onset of severe headaches associated with altered language and uncoordinated hand movements. During the examination, we

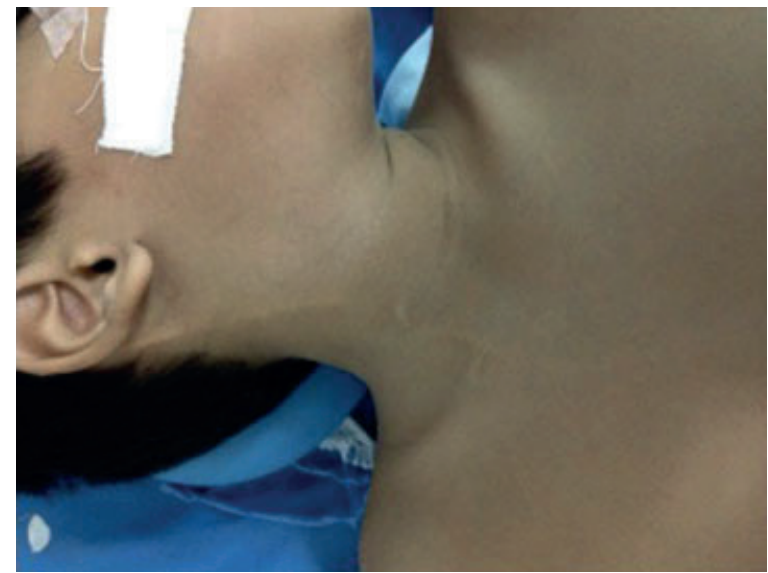

Fig. 1 Discontinuation of ventriculoperitoneal shunt at the neck.

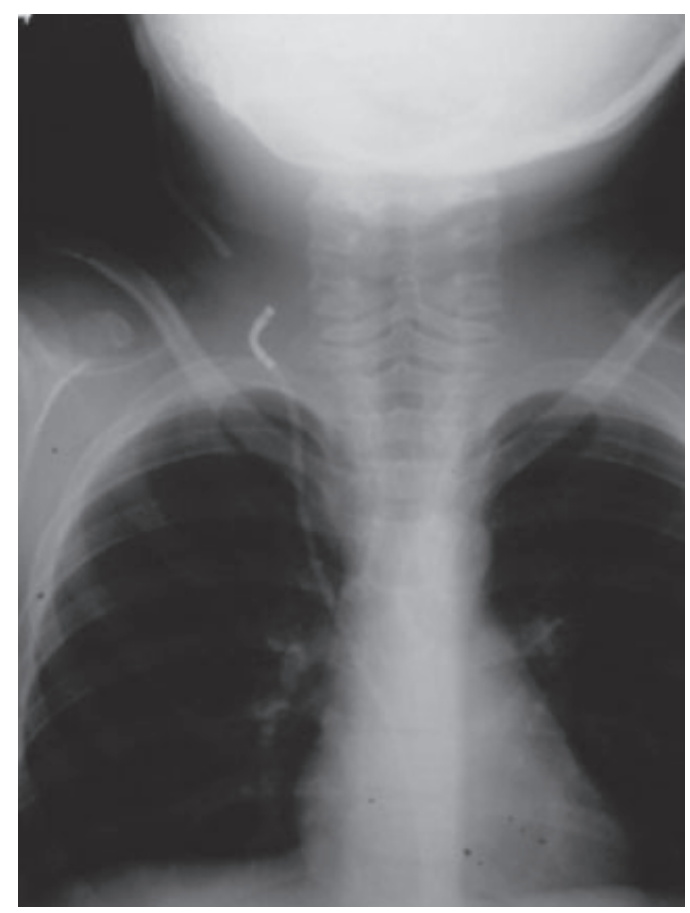

Fig. 2 Patient X-ray: disconnection at the place of trauma.

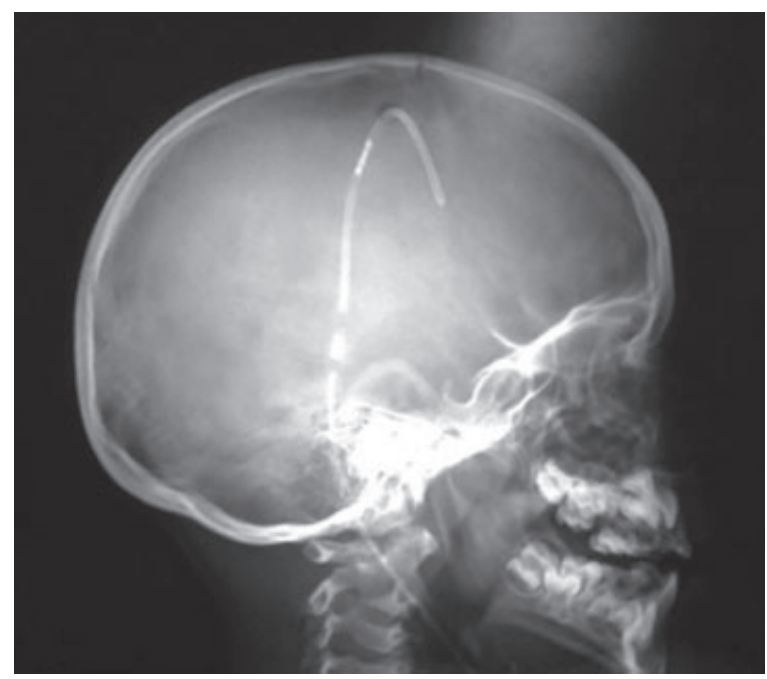

Fig. 3 Patient cranial X-ray. 


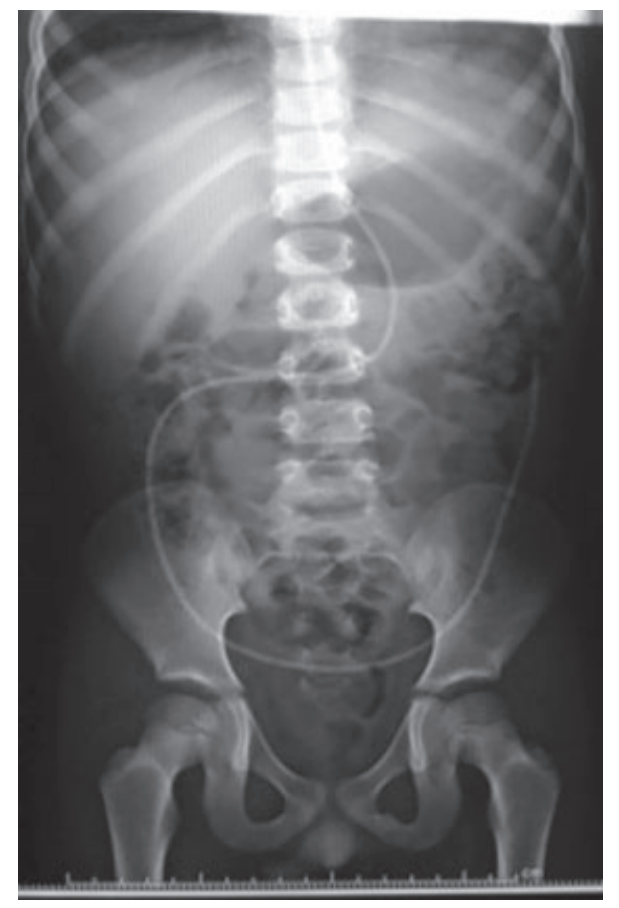

Fig. 4 Patient abdominal X-ray.

discovered a lump on the right side of the chest above the catheter's path. It was apparently associated with trauma related to a blow with a soccer ball he had received 3 days earlier.

During his stay in the emergency department, a set of radiological images was performed. The chest X-ray showed the system was disconnected at the level of the right thoracic region. The cranial and abdominal X-rays did not show abnormalities of the catheter, and cranial CT showed incipient ventricular enlargement (-Figs. 5-7).

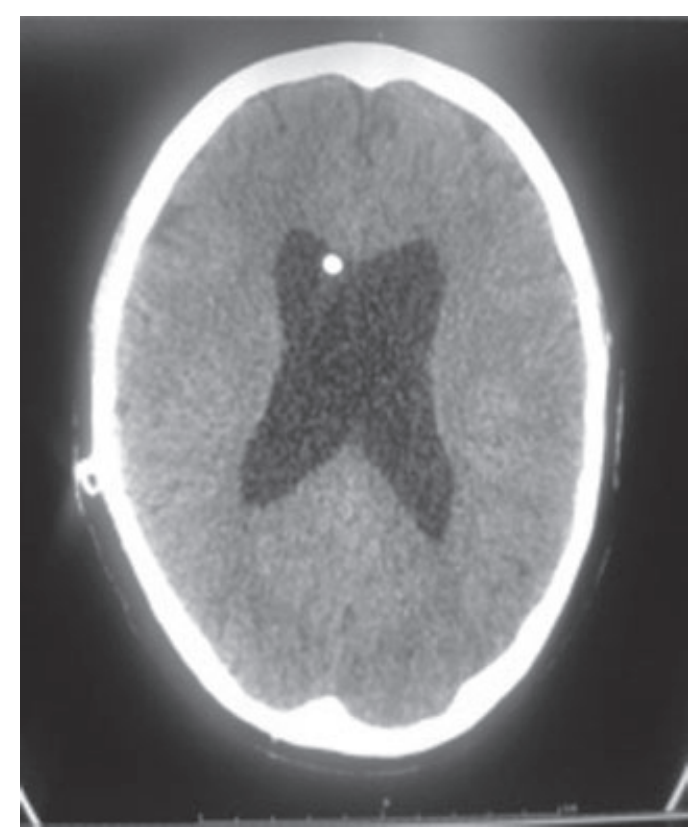

Fig. 5 Computed tomography: ventricular enlargement.

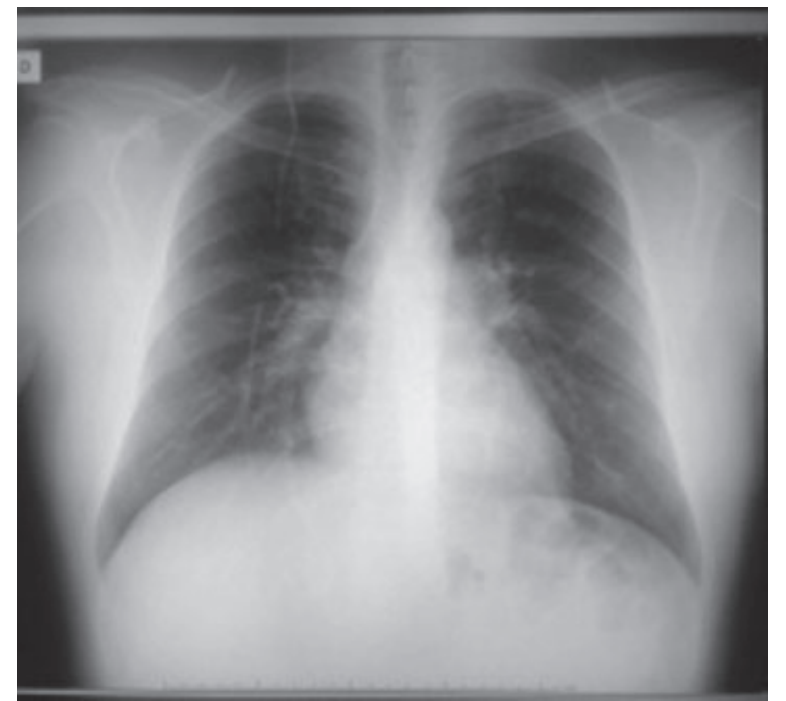

Fig. 6 Chest $\mathrm{X}$-ray: ventriculoperitoneal shunt disconnection at right thoracic region.

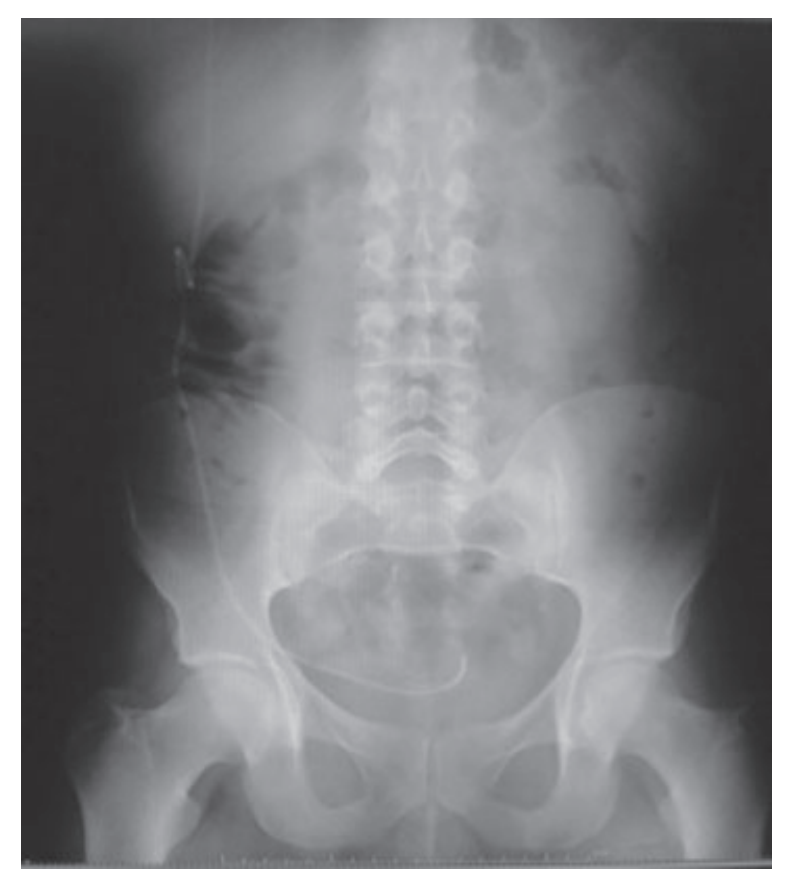

Fig. 7 Patient abdominal X-ray.

The patient needed surgical intervention to take a closer look at the catheter located at the thoracic segment and deal with the problems it created. These procedures were performed under general anesthesia. The patient was positioned, and the surface of the right cervical area, cranium, right lateral chest, and abdomen were prepared aseptically for surgery. During the surgery, we saw that the valve catheter was disconnected at the thoracic segment on its distal portion. The presence of granuloma was evident around the catheter (the lump that was obvious at the initial physical examination) ( - Fig. 8), without evidence of CSF collection. It was confirmed that the catheter 


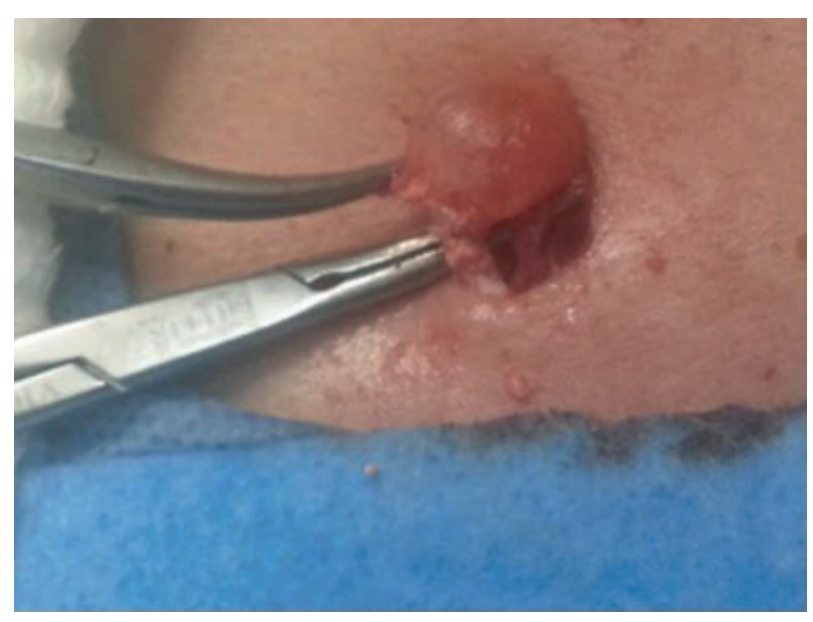

Fig. 8 Granuloma.

was functioning. The patient awoke active. The signs and symptoms of the initial presentation improved radically 3 hours after the surgery.

The patient continued checkups every 6 months with adequate clinical evolution, a complete absence of symptoms associated with an increase in intracranial pressure, and appropriate functioning of the VPS system.

\section{Discussion}

Congenital hydrocephalus occurs in 3 to 4 of 1,000 newborns worldwide. ${ }^{5,6}$ Hydrocephalus still represents a challenge for neurosurgeons to manage successfully and ensure the best possible quality of life for these patients. As soon as they understood the pathophysiology of the disease, surgeons have been able to manage it by implanting a shunt system. In 1989, Ferguson made the first CSF shunt peritoneum, and in 1949, Nulsen added a valve to the derivative system. ${ }^{2}$ Refinement of this technique has become first-line management for hydrocephalus for more than 40 years.

The VP shunt consists of the proximal catheter, the reservoir/valve, and the distal catheter in the peritoneum. The catheters are typically made of silicon and have a diameter of 2 to $3 \mathrm{~mm}$. In patients with contraindications to a peritoneal shunt, the devices may terminate in the pleural cavity or right atrium of the heart. ${ }^{7}$ The procedure has been widely used to treat hydrocephalus. An estimated 30,000 of these surgical interventions are done every year in the United States..$^{3,8,9}$ One of the physiological mechanisms involved is the fact that the peritoneum has a big cavity that possesses a high index of absorption of CSF ( $450 \mathrm{~mL}$ produced daily). ${ }^{4,5}$

Since the first applications of the shunt system, dysfunction has been considered a serious problem. Dysfunction is defined as the "failure of the shunt system which persists after placement for hydrocephalus and requires revision or replacement." ${ }^{6}$ Complications of this surgery can be divided into two categories: early onset (within 30 days of placement) and late onset (after 30 days). ${ }^{1}$ Shunt systems have the risk of complications such as overdrainage, mechanical dysfunction, occlusion, valvular failure, effects of growth in children, infection, catheter migration, and other less common problems. ${ }^{10}$ In the pediatric population, these complications occur in $14 \%$ of the patients through the first month after the implantation of the catheter and in 40 to $50 \%$ of patients after the first year of the implantation, ${ }^{6}$ in which $40 \%$ are due to the mechanical dysfunction of the VPS catheter. ${ }^{4,11}$ Shunt fracture, disconnection, and migration to various cavities are rarely seen. ${ }^{5,6,11}$

The early diagnosis of shunt system dysfunction is vital for the treatment's success. Health professionals must be knowledgeable about the main symptoms of shunt failure: nausea and vomiting (positive predictive value [PPV]: 79\%), irritability (PPV: 78\%) decreased level of consciousness (PPV: 100\%), and a bulging fontanel (PPV: 92\%). ${ }^{12}$ These symptoms tend to appear 5 days after the disconnection. Because some cases do not present any symptoms, imaging diagnostic methods play a major role in helping identify these types of complications. The disconnection can appear at any point on the catheter's path; it is more frequent at the cervical level., ${ }^{4,5,13-15}$

Shunt disconnection is a rare cause of shunt failure in children. ${ }^{16}$ It is most common in early childhood and the preschool stage. Fractures of the shunt catheter occur at these ages. The disconnection is usually due to loose ligation and stretching of the shunt catheter between two fixed points. The shunt catheter may be fixed to subcutaneous tissue by calcification that leads to its fracture principally in the neck and thoracic region. ${ }^{14,15}$ The diagnoses of shunt disconnection in patients with a previous diagnosis of hydrocephalus are based on clinical presentation and findings in diagnostic images that are often reached using a shunt series (anteroposterior [AP]/lateral skull, AP chest, and kidneys, ureters, bladder). These are the most sensitive diagnostic options ${ }^{7,17}$; it is not necessary to measure intracranial pressure. However, there is not enough research that shows the rate of fracture in any place of the catheter distal to the fixed points.

For patients who show a disconnection of the VPS system, the treatment should be surgical intervention, ideally done within the first 24 hours after the appearance of the first symptoms. ${ }^{5,6,8,11}$ Not only does the trauma associated with this procedure raise some concerns, but also the surgical intervention and its associated risks appear to be greater in the pediatric population. It is also important to highlight the social inconvenience of transporting the patient from one place to another that can increase the cost significantly (now $\$ 94$ million per year in the United States). ${ }^{3,6,18}$ Retrospective studies show that 49 to $59 \%$ of all patients of all ages with a VPS system will require a surgical procedure at some point in their lives due to associated complications. Reducing these mechanical complications should be the main goal for all brain surgeons and the patients who undergo this process. It is believed that using a one-piece shunt system may provide 
the best way to avoid the potential complications due to shunt disconnection. ${ }^{6,9,11}$

Current first-year failure rates for shunts inserted in adults fell at a rate of just over $0.02 \%$ per year; however, late failure rates in adults have actually risen at a significant rate of $0.05 \%$ per year, ${ }^{10,19}$ whereas it is just the opposite in children. This trend implies a greater number of surgical interventions for adults. These results should not be taken lightly and should raise concern among neurosurgeons. ${ }^{18,20}$

This article is a call for research to strengthen the materials and properties of the catheters and avoid spontaneous and traumatic fractures in the VPS path and the fatal complications associated with it.

\section{Acknowledgments}

We thank Sebastian Toro and David Vega for helping in collecting information during the development of this article.

\section{References}

1 Erwinovna E, Pichilingue P, Quiches B, Quintanilla B. Complicaciones en el tratamiento quirúrgico de pacientes pediátricos con hidrocefalia operados en el Hospital Nacional Guillermo Almenara Irigoyen. Acta Med Per 2011;28(01):6-11

2 Aurrecoechea PJ, Menchacatorre M, Urigüen J, Zorrilla GJ. Derivaciones de líquido cefalorraquídeo. Resultados y complicaciones. Neurocirugia 1995;6:205-210

3 Olson S. The problematic slit ventricle syndrome. A review of the literature and proposed algorithm for treatment. Pediatr Neurosurg 2004;40(06):264-269

4 Mendez A, Taboada M, Michavila N, Rodríguez E, Auad R. Diferentes complicaciones de los sistemas de derivación ventriculoperitoneal. MATSA - Fundación para la comunidadLaprida 533 - San Miguel de Tucumán - (400) Tucumán; SAR- FAARDIT2006

5 Diagnóstico y manejo de Hidrocefalia congénita y adquirida en menores de un año, Mexico Secretaria de Salud. 2011. Available at http://www.cenetec.salud.gob.mx/descargas/gpc/CatalogoMaestro/248_GPC_Hidrocefalia/IMSS-248-09-GER_Hidrocefalia.pdf

6 Borgbjerg BM, Gjerris F, Albeck MJ, Hauerberg J, Børgesen SE. Frequency and causes of shunt revisions in different cerebrospinal fluid shunt types. Acta Neurochir (Wien) 1995;136 (3-4):189-194
7 Sivaganesan A, Krishnamurthy R, Sahni D, Viswanathan C. Neuroimaging of ventriculoperitoneal shunt complications in children. Pediatr Radiol 2012;42(09):1029-1046

8 Oi S. Hydrocephalus research update-controversies in definition and classification of hydrocephalus. Neurol Med Chir (Tokyo) 2010;50(09):859-869

9 Çakin H, Kaplan M, Öztürk S, Kazez A. Intrathoracic migration of ventriculoperitoneal shunt through the Morgagni's hernia in case with Down syndrome: a rare shunt complication. Neurol India 2013;61(05):552-553

10 Stein SC, Guo W. Have we made progress in preventing shunt failure? A critical analysis. J Neurosurg Pediatr 2008; $1(01): 40-47$

11 Gómez López L, Luaces Cubells C, Costa Clará JM, et al. Complicaciones de las válvulas de derivación de líquido cefalorraquídeo. An Esp Pediatr 1998;4:368-370

12 Garton HJ, Kestle JR, Drake JM. Predicting shunt failure on the basis of clinical symptoms and signs in children. J Neurosurg 2001;94(02):202-210

13 Aldrich EF, Harmann P. Disconnection as a cause of ventriculoperitoneal shunt malfunction in multicomponent shunt systems. Pediatr Neurosurg 1990-1991-1991; 16(06):309-311 discussion 312

14 Lo WB, Ramirez R, Rodrigues D, Solanki GA. Ventriculoperitoneal shunt disconnection associated with spontaneous knot formation in the peritoneal catheter. BMJ Case Rep 2013;2013(13):bcr2013009590

15 Ghotme K, Drake J, Lamberti-Pasculli M. Management of Shunt Disconnections and Fractures in Children: Experience at the Hospital for Sick Children. AANS Pediatric Section Meeting. South Beach, FL

16 Drake JM, Sainte-Rose C. Shunt complications. Drake JM, Sainte-Rose C. The Shunt Book. Cambridge, MA: Blackwell Science; 1995

17 McGirt MJ, Zaas A, Fuchs HE, George TM, Kaye K, Sexton DJ. Risk factors for pediatric ventriculoperitoneal shunt infection and predictors of infectious pathogens. Clin Infect Dis 2003;36(07):858-862

18 Borcek AO, Civi S, Golen M, Emmez H, Baykaner MK. An unusual ventriculoperitoneal shunt complication: spontaneous knot formation. Turk Neurosurg 2012;22(02):261-264

19 Sharifian A, Abdollahi A, Maddah G, et al. Spontaneous transanal protrusion of ventriculoperitoneal catheter: a case report. Acta Med Iran 2013;51(02):135-138

20 Zhou F, Liu Q, Ying G, Zhu X. Delayed intracerebral hemorrhage secondary to ventriculoperitoneal shunt: two case reports and a literature review. Int J Med Sci 2012;9(01):65-67 